\section{RMD Open}

Rheumatic \&

Musculoskeletal Diseases

\title{
High body mass index is associated with increased risk for osteoarthritis of the first carpometacarpal joint during more than 30 years of follow-up
}

\author{
Mattias Rydberg (DD, ${ }^{1,2}$ Lars B Dahlin, ${ }^{1,2}$ Anders Gottsäter, ${ }^{3}$ Peter M Nilsson, ${ }^{4,5}$ \\ Olle Melander, ${ }^{4,5}$ Malin Zimmerman ${ }^{1,2}$
}

To cite: Rydberg M, Dahlin LB, Gottsäter A, et al. High body mass index is associated with increased risk for osteoarthritis of the first carpometacarpal joint during more than 30 years of follow-up. RMD Open 2020;6: e001368. doi:10.1136/ rmdopen-2020-001368

- Supplemental material is published online only. To view please visit the journal online (http://dx.doi.org/10.1136/rmdo pen-2020-001368).

Received 18 June 2020 Revised 28 August 2020 Accepted 11 October 2020
Check for updates

(C) Author(s) (or their employer(s)) 2020. Re-use permitted under CC BY-NC. No commercial re-use. See rights and permissions. Published by BMJ.

For numbered affiliations see end of article.

Correspondence to

Mattias Rydberg;

mattias.rydberg@med.lu.se

\section{ABSTRACT}

Introduction Osteoarthritis $(\mathrm{OA})$ of the first carpometacarpal (CMC-1) joint is a common hand disorder with symptoms including pain and weakness of the thumb. Previous studies have associated high BMI with $\mathrm{OA}$ of weight-bearing joints, whereas studies regarding non-weight-bearing joints have shown conflicting results. Thus, the aim of this study was to investigate the influence of overweight and obesity on incident $\mathrm{OA}$ of the $\mathrm{CMC}-1$ joint.

Method During 1974 to 1992, 33346 participants aged 26-61 years were included in the population-based cohort Malmö Preventive Project. Endpoint data were retrieved from Swedish national registers until end of 2018. Sexstratified Cox regression models adjusted for potential confounders were calculated using BMI as a continuous variable and stratified for normal weight, overweight and obesity.

Results Median follow-up was 36 years for men and 32 years for women. A one-unit increment of BMI was independently associated with incident $\mathrm{OA}$ of the $\mathrm{CMC}-1$ joint in men (HR 1.12; $95 \% \mathrm{Cl} 1.09$ to $1.15, \mathrm{p}<0.001$ ) and women (HR 1.05; 95\% Cl 1.03 to 1.08, $p<0.001$ ). Stratifying for BMI groups, obesity was independently associated with OA of the CMC-1 joint in men (HR 3.57; $95 \% \mathrm{Cl} 2.68$ to 4.77 , $\mathrm{p}<0.001)$ and women (HR 1.98; $95 \% \mathrm{Cl} 1.44$ to 2.73 , $\mathrm{p}<0.001)$.

Conclusion High BMI and obesity are major risk factors for OA of the CMC-1 joint. The association was stronger among men but could be demonstrated also among women. Future studies are warranted to clarify underlying pathophysiological mechanisms for this association, enabling identification of potential therapeutic targets related to obesity in order to prevent the development of $\mathrm{OA}$ of the CMC-1 joint.

\section{INTRODUCTION}

Osteoarthritis (OA) of the first carpometacarpal (CMC-1) joint of the thumb is a common hand disorder with an estimated symptomatic prevalence up to $15 \%$ in adults over 30 years $^{1}$ and a radiographical

\section{Key messages}

What is already known about this subject?

- Overweight and obesity have previously been associated with osteoarthritis of weight-bearing joints, for example, the knee and hip joint.

- Studies regarding the impact of obesity on the development of osteoarthritis of non-weight-bearing joints, for example, the first carpometacarpal joint, have shown conflicting results.

What does this study add?

- Using longitudinal data from over 33000 participants followed a median of 33 years, this study establishes obesity as a major risk factor for the development of osteoarthritis of the first metacarpal joint.

How might this impact on clinical practice?

- This study emphasises the importance of primary prevention and measures taken against the obesity epidemic.

- Future studies are warranted to clarify underlying pathophysiological mechanisms for the association found in this study, enabling identification of potential therapeutic targets related to obesity in order to prevent the development of osteoarthritis in the first carpometacarpal joint.

prevalence over $90 \%$ in people over 80 years. $^{2}$ Symptoms include pain, swelling, weakness and loss of function of the thumb, although the correlation between clinical symptoms and radiographic signs of $\mathrm{OA}$ has been reported to be low. ${ }^{3}$ Treatment includes both conservative regimes with application of orthosis, sometimes combined with intraarticular steroid injections, ${ }^{4}$ and a variety of surgical procedures. ${ }^{5}$ OA of the CMC-1 joint can present as the only affected joint in the hand or as a more generalised hand OA together with, for example, Bouchard's or Heberden's OA. ${ }^{6}$ 
Several risk factors for general hand OA have been proposed, for example, hypertension, ${ }^{7}$ hypermobility of joints, ${ }^{8}$ genetic factors, ${ }^{9}$ and occupational strain, ${ }^{10}$ although risk factors for specific types of hand OA are much less thoroughly studied. ${ }^{9}$ Overweight and obesity have been established as risk factors for OA in weightbearing joints, for example, the hip, ${ }^{11}$ knee, ${ }^{12}$ foot ${ }^{13}$ and spine, ${ }^{14}{ }^{15}$ partly through activation of certain inflammatory pathways by pro-inflammatory adipokines. ${ }^{16}$ However, data regarding the impact of body mass index (BMI) on non-weight-bearing joints, including general hand $\mathrm{OA}$ and specifically OA of the CMC-1 joint, have been reported with conflicting results. ${ }^{11} 17$

Thus, the aim of this study was to investigate the influence of overweight and obesity on incident $\mathrm{OA}$ of the CMC-1 joint of the thumb during $>30$ years of follow-up, using data from the Malmö Preventive Project (MPP); a large population-based cohort of over 33000 individuals from the city of Malmö, Sweden. ${ }^{18}$

\section{SUBJECTS AND METHODS}

\section{Study population and baseline data}

The MPP study was started in 1974 by the Department of Preventive Medicine at Malmö University Hospital, Sweden, as a screening programme for cardiovascular risk factors, alcohol consumption and breast cancer. Men and women were invited between 1974 and 1992 to participate in a health survey with a self-administrated questionnaire, screening for cardiovascular risk factors and laboratory blood test under fasting conditions. In total, 22444 males and 10902 females aged 26-61 years were included with an attendance rate of $71.2 \%$. The recruitment process has previously been described in detail. ${ }^{18}$ Participants had their height and weight measured and BMI $\left(\mathrm{kg} / \mathrm{m}^{2}\right)$ was calculated. Blood pressure (BP) was measured in a supine position and hypertension was defined as a systolic BP $\geq 140$ or diastolic BP $\geq 90 .{ }^{19}$ Smoking was self-reported and dichotomised into current smoker or non-smoker at baseline. Prevalent diabetes mellitus (DM) was defined as a self-reported physician's diagnosis, a fasting plasma glucose $\geq 7.0 \mathrm{mmol} / \mathrm{L}$, or current pharmacological treatment for diabetes. Occupational data were retrieved from the Swedish national censuses carried out 1970, 1980, 1985 and 1990 with self-reported job titles. The reported job title closest to screening date in MPP was used, and participants were classified as manual workers, including farming, and non-manual workers. ${ }^{20}$

\section{Endpoints and follow-up}

Follow-up started at a participant's baseline screening date and all individuals were followed until either an endpoint diagnosis, that is, OA of the CMC-1 joint, death, emigration, or end of study on 31 December 2018, whichever occurred first. For endpoint retrieval, the unique personal identification numbers of study participants were linked to several other Swedish national registers administered by the Swedish National Board of Health and Welfare previously described in detail, ${ }^{21}$ including the inpatient register from study start, the day surgery register from 1997, and the specialised outpatient register from 2000. The date of a diagnosis in any of the three registers was used as endpoint and end of follow-up. Prevalent diagnoses of OA of the CMC-1 joint, that is, a diagnosis before study entry, were retrieved from the same registers. All diagnoses had been made by physicians in a specialised care setting, using both clinical and radiographical diagnostics. The International Classification of Disease (ICD) version 8, 9 or 10 codes used were 713.08, 713.09, 715B and M18.9, respectively. No surgical codes were used for endpoint retrieval.

\section{Excluded participants}

Since the primary endpoint of this study was to investigate the effect of overweight and obesity, using normal weight subjects as reference, 622 participants with underweight, that is, BMI $<18.5 \mathrm{~kg} / \mathrm{m}^{2}$, were excluded from analysis. A total of 14 participants had missing data on BMI and were also excluded from further analysis. Finally, 50 participants with a prior diagnosis of OA of the CMC-1 joint at baseline were excluded (figure 1).

\section{Statistical analysis}

Quantitative baseline variables were presented as mean with SD (SD) or median with IQR if distribution was normal or skewed, respectively. Nominal data were presented as counts and proportions. BMI was separated into three categories; $<25$ (normal weight), $\geq 25$ to $<30$ (overweight) and $\geq 30$ (obesity) $\mathrm{kg} / \mathrm{m}^{2}$, as defined by the WHO. ${ }^{22}$

To analyse the effect of increasing BMI on incident OA of the CMC-1 joint, Cox proportional hazard regression models, stratified for sex, were used. Two models were created; the first adjusting only for age at study entry.

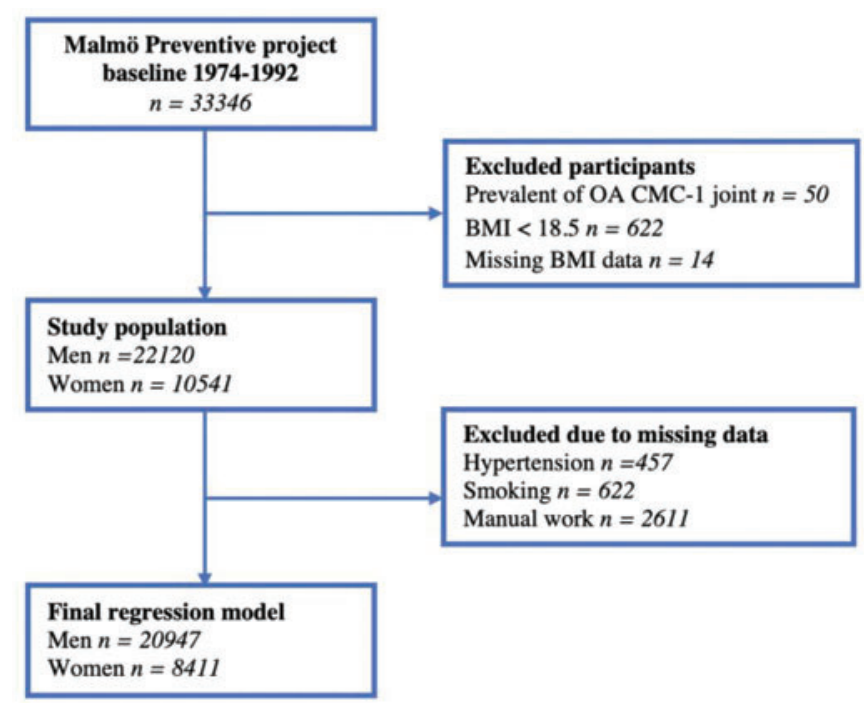

Figure 1 Derivation of the study cohort from Malmö Preventive Project. BMI, body mass index; CMC-1, first carpometacarpal joint; OA, osteoarthritis. 
Second, a multivariate Cox regression model was fitted and adjusted for potential confounders; age at study entry, current smoking at baseline, hypertension, prevalent diabetes and manual work that is, variables previously associated with OA. ${ }^{7102324}$ Participants with missing data on confounder variables were excluded from respective regression analysis (figure 1). HR with $95 \%$ CI were expressed using subjects with normal weight as reference when using BMI as an ordinal variable, and $\mathrm{HR}$ with $95 \%$ CI for a one-unit increment of BMI when using BMI as a continuous variable.

Furthermore, Kaplan-Meier (KM) plots were used to calculate cumulative incidences of $\mathrm{OA}$ of the CMC1 joint in each BMI group and a log-rank test was used to compare differences in event-free time. To assess potential violation of the proportional hazard assumption, log-log plots and KM curves were analysed and no violation was found. To test for potential interaction between age and BMI, an interaction variable (age*BMI) was introduced on top of the ageadjusted Cox regression model and analysed. Furthermore, to test for potential interaction between manual work and BMI, an interaction variable (manual work*BMI) was also introduced in a Cox regression model and analysed. Finally, a sensitivity analysis, excluding participants with a follow-up time over 30 years in the fully adjusted Cox regression model, was performed and analysed.
IMB SPSS statistics for MAC version 25 (SPSS Inc., Chicago, Illinois, USA) were used for all statistical analysis. A two-sided $p<0.05$ was considered significant.

\section{RESULTS}

\section{Baseline characteristics}

Of the 622 participants excluded due to a BMI $<18.5$ (figure 1), $1.8 \%(11 / 622)$ had an incident diagnosis of OA of the CMC-1 joint during follow-up. All other participant characteristics at baseline are displayed in table 1 , stratified for BMI group, and table 2, stratified for sex.

\section{Incident $\mathrm{OA}$ of the CMC-1 joint by BMI and sex}

Median follow-up was 36 [IQR 13.3] years for men and 32 [IQR 8.6] years for women. In total, 478 men (478/ 22 120, 2.2\%) and 444 women $(444 / 10541,4.2 \%)$ were diagnosed with $\mathrm{OA}$ of the $\mathrm{CMC}-1$ joint during follow-up. This corresponds to an incidence of 0.70 cases per 1000person years for men and 1.45 cases per 1000 person-years for women, respectively.

Using univariate KM plots, there was a shorter event-free time, that is, time without a diagnosis of OA of the CMC-1 joint, among overweight and obese participants compared with normal weight participants, both when analysing all participants (figure 2) (log-rank test $\mathrm{p}<0.001$ ), but also stratified for men $(\log$-rank test $\mathrm{p}<0.001)$ and women $(\log$ rank test $\mathrm{p}<0.001)$.

Table 1 Participant characteristics at baseline, stratified for sex and BMI group. Normal weight, $\mathrm{BMI}<25$; overweight, $\mathrm{BMI} \geq 25$ to $<30$; obesity, $\mathrm{BMI} \geq 30$. Participants with a $\mathrm{BMI}<18.5$ and prevalent $\mathrm{OA}$ of $\mathrm{CMC}-1$ joint were excluded

\begin{tabular}{|c|c|c|c|}
\hline A. Male participants & Normal weight $n=12790$ & Overweight $n=7949$ & Obesity $n=1381$ \\
\hline Age, years $( \pm S D)$ & $43 \pm 6.6$ & $44.6 \pm 6.4$ & $45.3 \pm 6.1$ \\
\hline $\operatorname{BMI}\left(\mathrm{kg} / \mathrm{m}^{2}\right)( \pm \mathrm{SD})$ & $22.6 \pm 1.6$ & $26.9 \pm 1.3$ & $33.4 \pm 2.4$ \\
\hline Current smoking (n, \%) & $6652(52.0)$ & $3579(45.0)$ & $586(42.4)$ \\
\hline Hypertension (n, \%) & 2885 (22.6) & 3092 (38.9) & $807(58.4)$ \\
\hline Prevalent diabetes $(\mathrm{n}, \%)$ & $297(2.3)$ & $306(3.8)$ & $167(12.1)$ \\
\hline Manual work (n, \%) & $4998(41.2)$ & $3511(46.4)$ & $651(51.9)$ \\
\hline Incident OA of the CMC-1 (n, \%) & $201(1.6)$ & $206(2.6)$ & $71(5.1)$ \\
\hline $\begin{array}{l}\text { Incidence rate of OA of the CMC- } 1 \\
\text { (cases/ } 1000 \text { person-years) }\end{array}$ & 0.5 & 0.8 & 1.9 \\
\hline B. Female participants & Normal weight $n=6642$ & Overweight $\mathrm{n}=2836$ & Obesity $n=1063$ \\
\hline Age, years $( \pm S D)$ & $48.6 \pm 7.8$ & $51.7 \pm 5.5$ & $52.2 \pm 5.4$ \\
\hline $\mathrm{BMI}\left(\mathrm{kg} / \mathrm{m}^{2}\right)( \pm \mathrm{SD})$ & $22.1 \pm 1.6$ & $27.0 \pm 1.4$ & $33.5 \pm 3.4$ \\
\hline Current smoking (n, \%) & $2513(37.8)$ & 807 (28.5) & $286(26.9)$ \\
\hline Hypertension (n, \%) & $1280(19.3)$ & $968(34.1)$ & $483(45.4)$ \\
\hline Prevalent diabetes $(\mathrm{n}, \%)$ & $123(1.9)$ & $153(5.4)$ & $139(13.1)$ \\
\hline Manual work (n, \%) & 2279 (38.3) & $1216(50.8)$ & $480(58.2)$ \\
\hline Incident OA of the CMC-1 (n, \%) & $250(3.8)$ & $130(4.6)$ & $64(6.0)$ \\
\hline $\begin{array}{l}\text { Incidence rate of OA of the CMC- } 1 \\
\text { (cases/1000 person-years) }\end{array}$ & 1.2 & 1.6 & 2.3 \\
\hline
\end{tabular}

BMI, body mass index; CMC-1, first carpometacarpal joint of the thumb; OA; osteoarthritis. 
Table 2 Baseline characteristics stratified for sex. Normal weight, $\mathrm{BMI}<25$; overweight, $\mathrm{BMI} \geq 25$ to $<30$; obese, $\mathrm{BMI}$ $\geq 30$. Participants with a $\mathrm{BMI}<18.5$ and prevalent $\mathrm{OA}$ of CMC-1 joint were excluded

\begin{tabular}{|c|c|c|}
\hline Characteristics & $\begin{array}{l}\text { Women } \\
(n=10541)\end{array}$ & $\begin{array}{l}\text { Men } \\
(n=22 \text { 120) }\end{array}$ \\
\hline Age, years ( $(\mathrm{SD})$ & $49.8 \pm 7.4$ & $43.7 \pm 6.6$ \\
\hline BMI $\left(\mathrm{kg} / \mathrm{m}^{2}\right)( \pm \mathrm{SD})$ & $24.6 \pm 4.1$ & $24.7 \pm 3.2$ \\
\hline Normal weight (n, \%) & $6642(63.0)$ & $12790(57.8)$ \\
\hline Overweight (n, \%) & 2836 (26.9) & 7949 (35.9) \\
\hline Obesity (n, \%) & $1063(10.1)$ & $1381(6.2)$ \\
\hline Current smoking (n, \%) & 3606 (34.2) & 10817 (48.9) \\
\hline Hypertension (n, \%) & 2731 (25.9) & $6784(30.7)$ \\
\hline Manual work (n, \%) & 3975 (43.4) & $9160(43.7)$ \\
\hline Prevalent diabetes (n, \%) & 415 (3.9) & $770(3.5)$ \\
\hline $\begin{array}{l}\text { Incident } \mathrm{OA} \text { of the } \mathrm{CMC}-1 \\
(\mathrm{n}, \%)\end{array}$ & $444(4.2)$ & $478(2.2)$ \\
\hline $\begin{array}{l}\text { Incidence rate of OA of } \\
\text { the CMC-1 } \\
\text { (cases/1000 person- } \\
\text { years) }\end{array}$ & 1.45 & 0.70 \\
\hline
\end{tabular}

CMC-1, first carpometacarpal joint; OA, osteoarthritis.
When using BMI as a continuous variable in the ageadjusted Cox regression model, a one-unit increment of BMI was independently associated with incident $\mathrm{OA}$ of the CMC-1 joint in both men (HR 1.12; 95\% CI 1.09 to $1.15 ; \mathrm{p}<0.001$ ) and women (HR $1.05 ; 95 \%$ CI 1.03 to 1.08 ; $\mathrm{p}<0.001)$. This association was not attenuated by further adjustment for hypertension, smoking, prevalent DM and manual work in the multivariate model (table 3 ).

Stratifying for BMI group, using normal weight participants as reference in the multivariate model, both overweight (HR 1.55; 95\% CI 1.27 to $1.90 ; \mathrm{p}<0.001$ ) and obesity (HR 3.57; 95\% CI 2.68 to 4.77 ; $\mathrm{p}<0.001$ ) among men were associated with incident OA of the CMC-1 joint Among women, only obesity (HR 1.98; $95 \%$ CI 1.44 to 2.73; $\mathrm{p}<0.001$ ) was associated with incident $\mathrm{OA}$ of the $\mathrm{CMC}-1$ joint (table 3).

\section{Sensitivity and interaction analysis}

In the sensitivity analysis, after excluding 20266 participants with a follow-up time over 30 years in the multivariate Cox regression model, BMI as a continuous variable was still associated with incident $\mathrm{OA}$ of the CMC-1 joint among men (HR 1.08; 95\% CI 1.05 to 1.11; $\mathrm{p}<0.001)$ and women (HR 1.03; $95 \%$ CI 1.00 to 1.05 ;

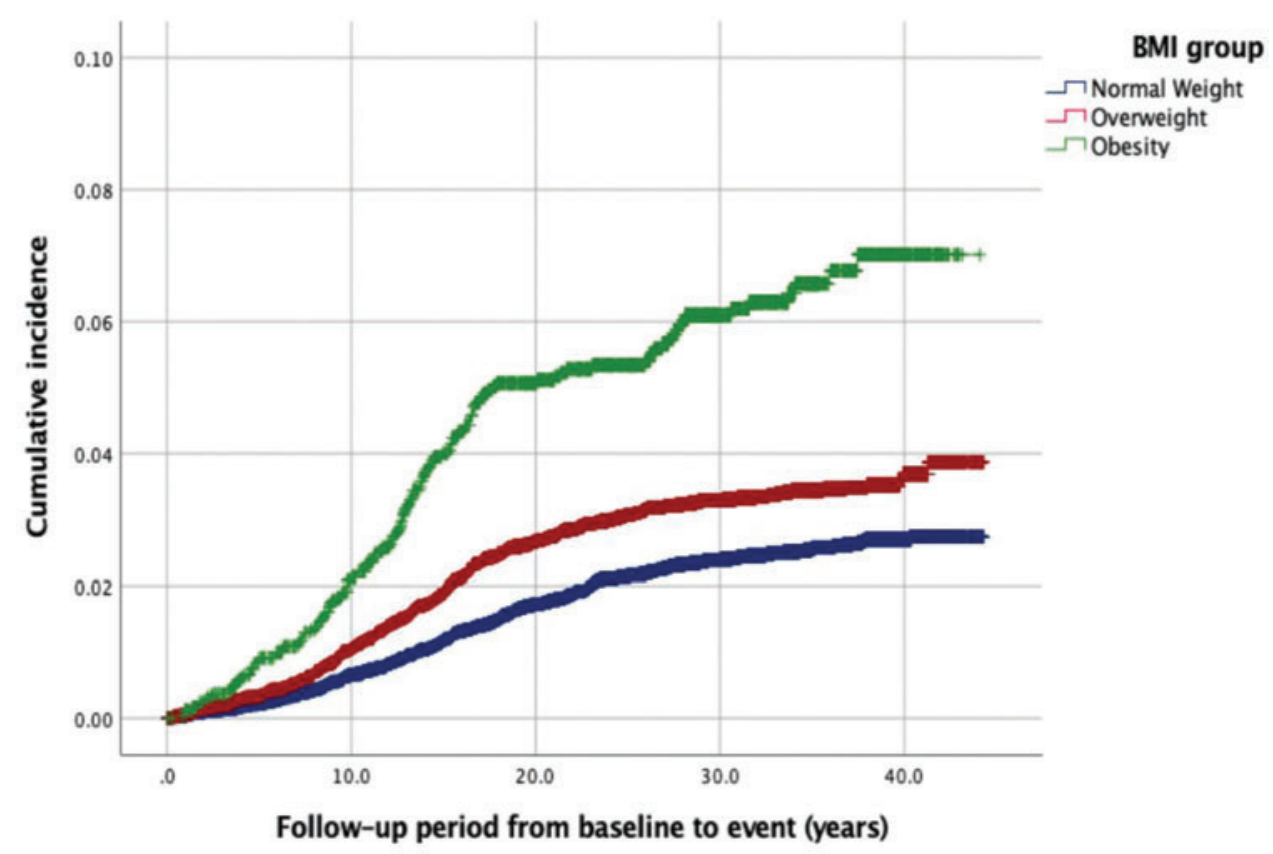

No. at risk:

$\begin{array}{lrrrrr}\text { Normal weight } & 19432 & 18451 & 16670 & 12798 & 2663 \\ \text { Overweight } & 10785 & 10159 & 8890 & 6455 & 1057 \\ \text { Obesity } & 2444 & 2223 & 1796 & 1013 & 112\end{array}$

Figure 2 Cumulative incidence of $\mathrm{OA}$ of the CMC-1 joint, stratifying for weight group during a follow-up of 40 years using Kaplan-Meier survival plots for all participants. Log-rank test for difference in survival distributions $p<0.001$. CMC-1, first carpometacarpal joint; No, number; OA, osteoarthritis. 
Table 3 Sex stratified, multivariate Cox regression analysis with HR for incident OA of the CMC-1 joint in relation to BMI as a continuous variable and for overweight and obese participants with normal weight participants as reference

\begin{tabular}{|c|c|c|c|c|}
\hline & \multicolumn{2}{|l|}{ Model I* } & \multicolumn{2}{|l|}{ Model II† } \\
\hline & HR (95\% Cl) & $P$ value & HR (95\% Cl) & $P$ value \\
\hline \multicolumn{5}{|l|}{ Men } \\
\hline BMI continuousł & $1.12(1.09-1.15)$ & $<0.001$ & $1.12(1.09-1.15)$ & $<0.001$ \\
\hline Normal weight & Reference & - & Reference & - \\
\hline Overweight & $1.52(1.25-1.85)$ & $<0.001$ & $1.55(1.27-1.90)$ & $<0.001$ \\
\hline Obesity & $3.41(2.58-4.49)$ & $<0.001$ & $3.57(2.68-4.77)$ & $<0.001$ \\
\hline \multicolumn{5}{|l|}{ Women } \\
\hline BMI continuous $\ddagger$ & $1.05(1.03-1.08)$ & $<0.001$ & $1.06(1.03-1.08)$ & $<0.001$ \\
\hline Normal weight & Reference & - & Reference & - \\
\hline Overweight & $1.23(0.97-1.57)$ & $=0.090$ & $1.27(0.98-1.63)$ & $=0.052$ \\
\hline Obesity & $1.88(1.38-2.57)$ & $<0.001$ & $1.98(1.44-2.73)$ & $<0.001$ \\
\hline
\end{tabular}

${ }^{*}$ Adjusted for age at study entry.

†Adjusted for age at study entry, hypertension, prevalent diabetes, manual work and smoking.

†HR expressed as per one unit increase of BMI.

$\mathrm{BMI}$, body mass index; CMC-1, first carpometacarpal joint; OA; osteoarthritis.

$\mathrm{P}=0.03)$. Furthermore, obesity was still associated with incident $\mathrm{OA}$ of the CMC-1 joint among both men (HR $2.27 ; 95 \%$ CI 1.68 to $3.06 ; \mathrm{p}<0.001$ ) and women (HR 1.40; $95 \%$ CI 1.01 to $1.94 ; \mathrm{p}<0.04$ ) (online supplemental table $1)$. No significant interactions were found between BMI and age, neither among men ( $p$ for interaction $=0.74$ ) or women ( $p$ for interaction=0.22), or between BMI and manual work, neither among men ( $\mathrm{p}$ for interaction $=0.47$ ) or women ( $\mathrm{p}$ for interaction $=0.94)$.

\section{DISCUSSION}

The main finding of this observational study was that obesity is independently associated with an increased risk of OA of the CMC-1 joint, especially among men, even though the CMC-1 joint is not a weight-bearing joint. Moreover, an exposure-response association was found with higher risk for a diagnosis of OA of the CMC-1 joint with increasing BMI, findings that were not attenuated by adjustment for other potential confounders, such as age, prevalent DM, smoking, manual work or hypertension. This is, to the best of our knowledge, the first study with long-term follow-up that has investigated and demonstrated the relationship between overweight, obesity and OA of the CMC-1 joint in both men and women.

\section{Incidence rate}

The incidences of OA of the CMC-1 joint in our study were 0.7 and 1.45 cases per 1000 person-years for men and women, respectively. These results are in line with a previous study from Southern Sweden, who also reported the incidence of symptomatic OA of the CMC1 joint during 15 years of follow-up. ${ }^{3}$ Incidence data, however, vary significantly between studies, not only due to different study methods and age-groups studied, but also due to differences in the definition of $\mathrm{OA}$ of the
CMC-1 joint. Studies using only radiographic diagnosis criteria often report higher incidence rates compared with studies using doctor-diagnosed incidence after selfsought care. In our study, all diagnoses were made by physicians in a specialised care setting, combining both clinical and radiographic definitions on patients referred for symptomatic $\mathrm{OA}$ of the $\mathrm{CMC}$-joint. In contrast to studies using only radiographic diagnosis criteria, we therefore report on the clinically relevant incidence rates. Furthermore, our study also has a longer followup compared with previous studies, and results are adjusted for potential confounding factors. ${ }^{3} 2526$

\section{Role of fat tissue in osteoarthritis}

In our study, higher BMI was associated with an increased risk of OA of the CMC-1 joint. Few earlier studies have investigated the relationship between BMI and specific types of hand $\mathrm{OA}$, and the results have been conflicting. ${ }^{17}$ In recent years, new evidence from both clinical and experimental studies have emerged, suggesting that obesity triggers a low-grade systemic inflammation, ${ }^{27}$ with associated increased production of adipokines, possibly leading to the development of $\mathrm{OA}$ in several joints. ${ }^{28}$ Proinflammatory adipokines, for example, leptin, produced in fat tissue, together with inflammatory cytokines, such as TNF- $\alpha$ and IL- 6 , have all been associated with the development of knee OA. ${ }^{29-31}$ Reliable data regarding inflammatory markers and the CMC-1 joint are, to our knowledge, lacking and the exact pathophysiology in which a low-grade systemic inflammatory due to obesity affects different joints has yet to be elucidated. Proposed mechanisms include decreased proteoglycan synthesis, ${ }^{28}$ degradation of cartilage matrix via IL-1 activated matrix metallopeptidases, ${ }^{16}$ and leptin-induced chondrocyte apoptosis. ${ }^{30}$ Thus, it is possible that increased serum levels of pro-inflammatory adipokines among overweight 
and obese individuals could at least partly explain our findings. However, as no inflammatory markers were related to the presently studied endpoints, we cannot draw any conclusions about such mechanisms from our results. Further studies are warranted to confirm this hypothesis.

\section{Role of sex}

In our study, overweight and obesity among men, but only obesity among women, were associated with OA of the CMC-1 joint. The association seemed to be stronger in men compared with women even when adjusting for smoking status, hypertension, manual work and DM in the multivariate Cox regression model (table 3). As previously stated, OA of the CMC-1 joint is more common among women, ${ }^{2}$ however, there are, to the best of our knowledge, no previous large, longitudinal studies addressing the impact of overweight and obesity on $\mathrm{OA}$ of the CMC-1 joint stratified for sex. Why overweight and obesity seems to affect the CMC-1 joint to a higher extent among men is difficult to answer. It is possible that other factors, for example, genetic ${ }^{9}$ or hormonal, ${ }^{32}$ that were not available for analysis in our study, are important. One can postulate that overweight, and particularly obesity, is upregulating different hormones associated with OA of the CMC-1 joint in previous studies, for example, relaxin, ${ }^{33}$ to a higher extent in men, thus potentially explaining the stronger association among men. Future studies should include both BMI and hormone levels to further investigate this hypothesis.

Furthermore, no interaction between BMI and manual work was found, neither among men or women. A recent study from Sweden has proposed a dose-response relationship between increasing occupational load and diagnosis of OA of the CMC-1 joint among men. ${ }^{10}$ In our study, we included manual work as a confounder both in the multivariate analysis and a separate interaction analysis and found no significant interaction. Thus, it is likely that other mechanisms, apart from manual work, explain the increased incidence of $\mathrm{OA}$ of the CMC-joint among men with overweight and obesity.

\section{Strengths and limitations}

The major strengths of this study are first the large number of participants, and the long follow-up, that is, over 30 years for women and 35 years for men. Secondly, the quality of baseline data, especially the meticulous anthropometric measurements, but also data collection concerning DM, are of high quality, making this study the largest longitudinal cohort studies analysing the effect of increasing BMI and OA of the CMC-1 joint, with available adjustment for DM, hypertension, manual work and smoking.

Nevertheless, there are several limitations to this study. First, other confounding factors, for which we were not available to adjust in the multivariate regression model, for example, alcohol consumption, hormone levels, or genetic influence might be involved in the development of OA of the CMC-1 joint. Potential interaction between obesity and serum hormonal levels would be of special interest since it might explain the stronger association found among men. There is also always a risk for residual confounding when adjusting for potential confounders in the regression models, as for example, smoking habits or working conditions may change over time. This should be kept in mind when interpreting our results.

Furthermore, obesity, especially in the elderly population, is known to be associated with chronic pain. The perception of pain is a subjective experience which, of course, differs from person to person. Both psychological, mechanical and hormonal factors have been suggested as mediators, explaining the association between obesity and chronic pain. ${ }^{34}$ From our study, we find it unlikely that the link between obesity and chronic pain without structural changes could explain the full association found between obesity and OA of the CMC-1 joint. This is especially true since the diagnosis is often established using a combination of clinical and radiological findings, indicating structural changes in the joint. Also, in a recent meta-analysis, ${ }^{17}$ a higher BMI was associated with radiographically diagnosed hand OA, also indicating a link between obesity and structural changes of hand joints causing pain.

Also, BMI was only measured once at baseline. During follow-up, participants may have lost or gained weight; thus, changed to another BMI sub-group before being diagnosed with OA of the CMC-1 joint. However, recent studies on BMI and ageing have proposed that weight gain is fairly constant throughout life, with exception of the years prior to death. ${ }^{35}$ How weight loss affects the risk of OA, and whether it could be used as a treatment for hand $\mathrm{OA}$ could be an interesting target for future investigations.

Furthermore, the study did not use standardised diagnostic criteria throughout follow-up. Still, the diagnosis in all patients was made in a specialised care setting, using clinical and radiological symptomatic diagnosis, rather than a strict radiological finding. Studies using this method might thus reflect a more clinically relevant incidence rate compared with studies using only radiological findings ${ }^{3}$; the latter being more frequently observed in the general population with increasing age. ${ }^{2}$ Even so, some participants might have been diagnosed only in primary healthcare, which might have lowered the incidence rates in our study somewhat.

Finally, like all cohort studies, there is always a risk for selection bias when including participants. It is possible that participants with a high BMI were more inclined to participate in the study, thus, influencing our results with an increasing prevalence of overweight and obese individuals. However, since our endpoint, that is, OA of the CMC-1 joint, was not mentioned in the original invitation, we have minimised the risk for selection bias based on this endpoint. Furthermore, the large number of participants that was recruited during several years reflect measurements taken against selection bias. 


\section{CONCLUSION}

High BMI and obesity constitute major risk factors for OA of the CMC-1 joint. The association was stronger among men, but could be demonstrated also in women. Future studies are warranted to clarify the underlying pathophysiological mechanisms for this association, enabling identification of potential therapeutic targets related to obesity in order to prevent the development of OA of the CMC-1 joint.

\section{Author affiliations}

${ }^{1}$ Department of Translational Medicine - Hand Surgery, Lunds University, Malmö, Sweden

2Department of Hand Surgery, Skånes University Hospital Malmö, Malmö, Sweden ${ }^{3}$ Department of Vascular Diseases, Skåne University Hospital Malmö, Malmö, Sweden

${ }^{4}$ Department of Clinical Science, Lund University, Skåne University Hospital Malmö, Malmö, Sweden

${ }^{5}$ Department of Internal Medicine, Lund University, Clinical Research Unit, Malmö, Sweden

Contributors A significant contribution was made by all authors stated in this article. MR, MZ and LBD designed the study, the first draft was made by MR and all authors contributed to the interpretation of the data. Finally, all authors reviewed and accepted the final version before publishing.

Funding The study was supported by the City of Malmö, the Swedish Medical Research Council, Swedish Diabetes Foundation, the Heart and Lung Foundation, Stig and Ragna Gorthons Foundation, Hulda Almroth Foundation, the Regional Agreement on Medical Training and Clinical Research (ALF) between Region Skåne and Lund University and local funds at Skåne University Hospital and Lund University.

Competing interests None declared.

Patient consent for publication Not required.

Patient and public involvement Neither patients and/or the public were involved in the design, planning or writing of this research.

Ethics approval All participants provided written informed consent. The study complied with the declaration of Helsinki and ethical approval, both for MPP (dnr: 2004/85) and for the present investigation (dnr: 2019-01439), were obtained by the Regional Ethical Review Board in Lund, Sweden.

Provenance and peer review Not commissioned; externally peer reviewed.

Data availability statement Data may be obtained from a third party and are not publicly available. The data used for this study can be applied for by contacting the Steering Committee of the Malmö Preventive Project (data manager Anders Dahlin, email: anders.dahlin@med.lu.se). For details of MPP and how to apply for data, see web site: www.malmo-kohorter.lu.se/english.

Supplemental material This content has been supplied by the author(s). It has not been vetted by BMJ Publishing Group Limited (BMJ) and may not have been peer-reviewed. Any opinions or recommendations discussed are solely those of the author(s) and are not endorsed by BMJ. BMJ disclaims all liability and responsibility arising from any reliance placed on the content. Where the content includes any translated material, BMJ does not warrant the accuracy and reliability of the translations (including but not limited to local regulations, clinical guidelines, terminology, drug names and drug dosages), and is not responsible for any error and/or omissions arising from translation and adaptation or otherwise.

Open access This is an open access article distributed in accordance with the Creative Commons Attribution Non Commercial (CC BY-NC 4.0) license, which permits others to distribute, remix, adapt, build upon this work non-commercially, and license their derivative works on different terms, provided the original work is properly cited, appropriate credit is given, any changes made indicated, and the use is non-commercial. See: http://creativecommons.org/licenses/by-nc/4.0/.

ORCID iD

Mattias Rydberg http://orcid.org/0000-0002-8249-8660

\section{REFERENCES}

1 Berger AJ, Meals RA. Management of osteoarthrosis of the thumb joints. J Hand Surg Am 2015;40:843-50.

2 Sodha S, Ring D, Zurakowski D, et al. Prevalence of osteoarthrosis of the trapeziometacarpal joint. J Bone Joint Surg Am 2005;87:2614-8.

3 Moriatis Wolf J, Turkiewicz A, Atroshi I, et al. Prevalence of doctor-diagnosed thumb carpometacarpal joint osteoarthritis: an analysis of Swedish health care. Arthritis Care Res (Hoboken) 2014;66:961-5.

4 Day CS, Gelberman R, Patel AA, et al. Basal joint osteoarthritis of the thumb: a prospective trial of steroid injection and splinting. J Hand Surg Am 2004;29:247-51.

5 Arnberg $\mathrm{H}$, Jack B, Niels T, et al. Osteoarthritis of the first carpometacarpal joint - patients subjective symptoms related to surgical outcome. Hand Microsurg 2018;7:63.

6 Kalichman L, Hernández-Molina G. Hand osteoarthritis: an epidemiological perspective. Semin Arthritis Rheum 2010;39:465-76.

7 Sanchez-Santos MT, Judge A, Gulati M, et al. Association of metabolic syndrome with knee and hand osteoarthritis: a community-based study of women. Semin Arthritis Rheum 2019;48:791-8.

8 Jónsson $\mathrm{H}$, Valtýsdóttir ST, Kjartansson $\mathrm{O}$, et al. Hypermobility associated with osteoarthritis of the thumb base: a clinical and radiological subset of hand osteoarthritis. Ann Rheum Dis 1996;55:540-3.

9 Kloppenburg M, van Beest S, Kroon FPB. Thumb base osteoarthritis: a hand osteoarthritis subset requiring a distinct approach. Best Pract Res Clin Rheumatol 2017;31:649-60.

10 Wolf JM, Turkiewicz A, Atroshi I, et al. Occupational load as a risk factor for clinically relevant base of thumb osteoarthritis. Occup Environ Med 2020;77:168-71.

11 Funck-Brentano T, Nethander M, Movérare-Skrtic S, et al. Causal factors for knee, hip, and hand osteoarthritis: a mendelian randomization study in the UK biobank. Arthritis Rheumatol 2019;71:1634-41.

12 Jiang L, Tian W, Wang Y, et al. Body mass index and susceptibility to knee osteoarthritis: a systematic review and meta-analysis. Joint Bone Spine 2012;79:291-7.

13 Thomas MJ, Peat G, Rathod T, et al. The epidemiology of symptomatic midfoot osteoarthritis in community-dwelling older adults: cross-sectional findings from the clinical assessment study of the foot. Arthritis Res Ther 2015;17:178.

14 Kalichman L, Guermazi A, Li L, et al. Association between age, sex, BMI and CT-evaluated spinal degeneration features. J Back Musculoskelet Rehabil 2009;22:189-95.

15 Tian W, Lv Y, Liu Y, et al. The high prevalence of symptomatic degenerative lumbar osteoarthritis in Chinese adults: a population-based study. Spine (Phila Pa 1976). 2014;39: 1301-10.

16 Wang T, He C. Pro-inflammatory cytokines: the link between obesity and osteoarthritis. Cytokine Growth Factor Rev 2018;44:38-50

17 Jiang L, Xie X, Wang Y, et al. Body mass index and hand osteoarthritis susceptibility: an updated meta-analysis. Int J Rheum Dis 2016;19:1244-54.

18 Berglund G, Nilsson P, Eriksson KF, et al. Long-term outcome of the malmo preventive project: mortality and cardiovascular morbidity. J Intern Med 2000;247:19-29.

19 Williams B, Mancia G, Spiering W, et al. 2018 ESC/ESH guidelines for the management of arterial hypertension. Eur Heart $J$ 2018;39:3021-104.

20 Statistics Sweden. 2020. Available https://www.scb.se/dokumenta tion/klassifikationer-och-standarder/socioekonomisk-indelning-sei/

21 Ludvigsson JF, Andersson E, Ekbom A, et al. External review and validation of the Swedish national inpatient register. BMC Public Health 2011;11:450-50.

22 WHO. Obesity and overweight. Fact sheet no. 311. 2020. Available https://wwwwhoint/en/news-room/fact-sheets/detail/obesity-andoverweight

23 Hui M, Doherty M, Zhang W. Does smoking protect against osteoarthritis? Meta-analysis of observational studies. Ann Rheum Dis 2011;70:1231-7.

24 Louati K, Vidal C, Berenbaum F, et al. Association between diabetes mellitus and osteoarthritis: systematic literature review and meta-analysis. RMD Open 2015;1:e000077.

25 Haugen IK, Englund M, Aliabadi P, et al. Prevalence, incidence and progression of hand osteoarthritis in the general population: the framingham osteoarthritis study. Ann Rheum Dis 2011;70:1581-6.

26 Snyder EA, Alvarez C, Golightly YM, et al. Incidence and progression of hand osteoarthritis in a large community-based cohort: the johnston county osteoarthritis project. Osteoarthritis Cartilage 2020;28:446-52. 
27 Pereira SS, Alvarez-Leite Jl. Low-grade inflammation, obesity, and diabetes. Curr Obes Rep 2014;3:422-31.

28 Thijssen E, van Caam A, van der Kraan PM. Obesity and osteoarthritis, more than just wear and tear: pivotal roles for inflamed adipose tissue and dyslipidaemia in obesity-induced osteoarthritis. Rheumatology (Oxford) 2015;54:588-600.

29 de Boer TN, van Spil WE, Huisman AM, et al. Serum adipokines in osteoarthritis; comparison with controls and relationship with local parameters of synovial inflammation and cartilage damage. Osteoarthritis Cartilage 2012;20:846-53.

$30 \mathrm{Gao} \mathrm{YH}$, Zhao CW, Liu B, et al. An update on the association between metabolic syndrome and osteoarthritis and on the potential role of leptin in osteoarthritis. Cytokine 2020;129:155043.
31 Kaneko S, Satoh T, Chiba J, et al. Interleukin-6 and interleukin-8 levels in serum and synovial fluid of patients with osteoarthritis. Cytokines Cell Mol Ther 2000;6:71-9.

32 Ouellette EA, Makowski AL. How men and women are affected by osteoarthritis of the hand. Orthop Clin N Am 2006;37:541-8.

33 Wolf JM, Scher DL, Etchill EW, et al. Relationship of relaxin hormone and thumb carpometacarpal joint arthritis. Clin Orthop Relat Res 2014;472:1130-7.

34 Okifuji A, Hare BD. The association between chronic pain and obesity. J Pain Res 2015;8:399-408.

35 Stenholm S, Simonsick EM, Ferrucci L. Secular trends in body weight in older men born between 1877 and 1941: the baltimore longitudinal study of aging. J Gerontol A Biol Sci Med Sci 2010;65:105-10. 